Volume 10, № 2, julho-dezembro 2014, Jataí-GO | ISSN: 1807-9342 DOI: 10.5216/rir.v10i2.28880 
Revista Itinerarius Reflectionis - UFG.

Volume 10, No 2, julho-dezembro 2014, Jataí-GO.

Semestral.

ISSN: $1807-9342$

\section{Universidade Federal de Goiás}

\section{Reitor}

Orlando Afonso Valle do Amaral

\section{Vice-Reitor}

Manoel Rodrigues Chaves

Pró-Reitoria de Graduação

Luiz Mello de Almeida Neto

\section{Regional Jataí}

Diretor: Wagner Gouvêa dos Santos

\section{Editores Responsáveis}

Eveline Borges Vilela-Ribeiro

José Sílvio Oliveira

Vânia Ramos Rodrigues 


\section{Sumário}

Ambientes virtuais de aprendizagem: o uso das tecnologias da informação e comunicação na prática pedagógica.................................5

Introduçáo ..................................................................................................7

Educação a Distância: algumas consideraçóes teóricas..........................8

AVA: o uso na educaçáo presencial e à distância ..................................16

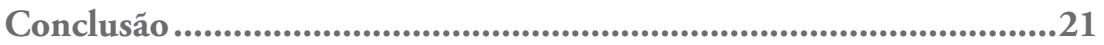




\title{
AMBIENTES VIRTUAIS DE APRENDIZAGEM: O USO DAS TECNOLOGIAS DA INFORMAÇÃO E COMUNICAÇÁO NA PRÁTICA PEDAGÓGICA
}

\author{
Fernando Carlos Alves da Silva \\ fcarlosas@hotmail.com \\ Universidade Estadual de Goiás
}

Geziel Alves Pereira alvesgeziel@hotmail.com Mestrando em História Cultural (PUC - GO)

Valdenir Maria Pereira Soares alvesvaldenir@yahoo.com Mestranda em História Cultural (PUC - GO)

\section{Resumo}

$\mathrm{Na}$ última década, as Tecnologias da Informação e Comunicação têm revolucionado o ambiente de ensino-aprendizagem criando novos espaços, novas ferramentas e métodos como subsídio para a realização deste processo. O objetivo deste artigo é buscar no referencial teórico analisado, reflexóes acerca do uso das tecnologias na produção de Ambientes Virtuais de Aprendizagem, assim, caracterizando o modelo de Educação a Distância, que experimenta vertiginosa expansão nos últimos anos. No que se refere aos ambientes virtuais, tido como ambiente do processo ensino-aprendizagem, apresentando seu potencial no cenário educacional contemporâneo, como uma nova ferramenta didático-pedagógica, de disseminação de conhecimentos e que atende aos anseios da crescente demanda por cursos superiores. Também seu potencial como apoio na educação presencial. A possibilidade da mudança da prática pedagógica não está nos ambientes virtuais de aprendizagem, mas na reflexão permanente do professor que avalia a sua prática com vistas ao seu aprimoramento. Os ambientes virtuais de aprendizagem são meios digitais que permitem a interatividade e a comunicação por meio do diálogo. Assim é possível vivenciar um processo educativo construtivo através do ambiente online. Como metodologia utilizamos levantamento bibliográfico acerca de estudos e autores que abordam o tema do uso das tecnologias na educação e dos ambientes virtuais.

Palavras-chave: Tecnologia. Educação. Ambientes Virtuais. 
Vol. 10, No 2, julho-dezembro 2014

VIRTUAL LEARNING ENVIRONMENTS: THE USE OF INFORMATION TECHNOLOGY AND

COMMUNICATION IN TEACHING PRACTICE

\begin{abstract}
In the past decade Information and Communication Technologies have revolutionized the teaching-learning environment by creating new spaces, new tools and methods as support for carrying out this process. The purpose of this article is to look at the theoretical framework analyzed, reflections on the use of technology in the production of virtual learning environments, thus characterizing the model of Distance Education, experiencing rapid expansion in recent years. With regard to virtual environments, considered the teachinglearning environment, showing its potential in the contemporary educational scene as a new pedagogical-didactic tool for disseminating knowledge and meets the expectations of the growing demand for higher education. Also it's potential as a support in regular education. The possibility of changing pedagogical practice is not in virtual learning environments, but in ongoing reflection of the teacher who evaluates their practice with a view to their improvement. Virtual learning environments are digital media that allow interactivity and communication through dialogue. So it is possible to experience a constructive educational process through the online environment. The methodology used literature concerning studies and authors that address the use of technology in education and virtual environments.
\end{abstract}

Keywords: Technology. Education. Virtual Environments. 


\section{Introdução}

Uma das possibilidades da educaçáo contemporânea e das tecnologias da informação e comunicação (TIC) é atender às necessidades da sociedade atual, através do desenvolvimento de procedimentos e métodos de ensino e de aprendizagem intermediados pelas ferramentas midiáticas. $\mathrm{O}$ uso das TIC como práticas pedagógicas, presenciais ou virtuais, é um desafio para os profissionais da educação e os ambientes virtuais de aprendizagem (AVA), como nova realidade do processo de ensino-aprendizagem, fazem parte deste desafio.

Os ambientes virtuais de aprendizagem (AVA) são uma interface acessada através da internet, podendo ser personalizada de acordo com as demandas de cada curso (como também as demandas individuais) através das possibilidades que este recurso oferece, seja pela iteração do aluno com o docente, com outros alunos e com as ferramentas didático-pedagógicas disponíveis. Os AVA reúnem múltiplos recursos de armazenamento, de pesquisa e de comunicação disponíveis na internet, fomentando através de ferramentas a gestão do processo ensino-aprendizagem, para a distribuição de conteúdo, comunicação e interação entre os sujeitos do processo educativo.

Por diversas características e pelas possibilidades de aproveitamento didático-pedagógico, os AVA têm sido utilizados como meios para dinamizar as práticas pedagógicas mesmo na educação presencial. Os docentes são mediadores do processo ensino-aprendizagem e devem saber tirar proveito dessas novas ferramentas, não apenas como uma nova ferramenta no cenário tradicional de educação, mas para gerar novas possibilidades de ensino-aprendizagem, de desenvolvimento cognitivo, havendo necessidade de refletir sobre as questôes didático-pedagógicas que emergem do ensino que utiliza os AVA. 
Portanto, para compreender as condiçóes nas quais se desenvolvem as experiências pedagógicas, fez-se através de revisão bibliográfica, uma leitura acerca do uso das TIC e dos AVA como ferramenta didático-pedagógica.

\section{Educação a Distância: algumas consideraçóes teóricas}

Há muito tempo, as TIC têm sido integradas aos projetos e cursos de Educação à Distância (EAD) com os objetivos de facilitar os processos de ensino e de aprendizagem e de estimular a colaboração e a interação entre seus sujeitos. Nesta perspectiva, a EAD é concebida como um novo formato ou modalidade de ensino e de aprendizagem. Existe certa diversidade em como definir o ensino a partir da introdução das TIC e dos AVA, tendo como pressupostos desta definiçáo diferentes elementos: a relação pedagógica, os recursos tecnológicos e a didática, por isso, iremos considerar alguns aspectos teóricos acerca da modalidade EAD no ensino.

A partir da relação entre o professor e o aluno, podem-se analisar alguns conceitos e definiçóes de EAD considerando a utilização dos meios e dos métodos na relação de aprendizagem. Esses meios e métodos estão vinculados a uma determinada abordagem didático-pedagógica.

A EAD pode então ser caracterizada como a modalidade de educação em que as atividades de ensino e de aprendizagem ocorrem independentemente de alunos e professores estarem no mesmo lugar e tempo. Definida sucintamente como:

[...] modalidade educacional na qual a mediação didático-pedagógica nos processos de ensino e aprendizagem ocorre com a utilizaçáo de meios e tecnologias de informação e comunicação, com estudantes e professores desenvolvendo atividades educativas em lugares ou tempos diversos. (BRASIL, 2005).

Neste sentido, podemos definir EAD como uma modalidade de educação, em que o aprendizado se dá em situação de distância física e 
temporal entre os sujeitos, midiatizada por alguma forma de tecnologia, responsável por permitir a comunicação e a interação entre os participantes.

A tecnologia é considerada importante, pois é o meio que promove a comunicação e a interação entre alunos e professores, já que eles não se encontram juntos em uma sala, como acontece na educação presencial.

Nesse sentido, Moran (2000) define a educação à distância como processo de ensino e de aprendizagem, mediado por tecnologias, no qual professores e alunos estão separados espacial e temporalmente. Dessa maneira, Sato (2000) destaca que a EAD deve ser adequada à realidade do aprendiz, desenvolvida por meio de práticas sociais críticas, criativas, que favoreçam uma atitude investigativa, autônoma, prazerosa, lúdica e que favoreça os momentos de comunicação.

Entre as variadas definiçóes de EAD está a sua distinção com educação presencial. De acordo com a Secretaria de Educação a Distância do Ministério da Educação (Seed/MEC), na EAD o aluno tem acesso ao conhecimento e desenvolve hábitos, habilidades e atitudes relativos ao estudo, à profissão e à sua própria vida, no tempo e local que lhe são adequados, não com a ajuda em tempo integral da aula de um professor, mas com a midiatização e com o apoio de materiais didáticos sistematicamente organizados, apresentados em diferentes suportes de informação, utilizados isoladamente ou combinados, através dos diversos meios de comunicação, o que não verificamos na educação presencial. (BRASIL, 2007).

Assim, podemos deduzir que existem diferenças entre a educação presencial e a EAD, mas ambas se complementam, mas, aparecendo principalmente como alternativa para a democratização do acesso ao ensino, principalmente ao ensino superior, atendendo especialmente a diversidade de alunos que não têm condiçốes de frequentar a escola no sistema presencial, por inúmeras razóes. 
Para Moore (2002) a EAD não representa apenas uma separação geográfica entre os sujeitos nela envolvidos no processo ensino-aprendizagem, mas, sobretudo, de um conceito didático-pedagógico.

Este universo de relaçóes pode ser ordenado segundo uma tipologia construída em torno dos componentes mais elementares deste campo - a saber, a estrutura dos programas educacionais, a interação entre alunos e professores, e a natureza e o grau de autonomia do aluno. (MOORE, 2002, p. 2).

Moore (2002) desenvolveu o conceito da distância transacional ${ }^{1}$. Neste conceito, a distância não se reduz unicamente à distância geográfica que separa o aluno do professor e dos demais alunos. Mas existe também a distancia temporal, entre o ato de ensinar (pelo docente) e o ato de aprender (discente).

$\mathrm{A} \mathrm{EAD}$ não se limita também às lacunas temporal e geográfica que existe entre o ato de ensino e o ato de aprendizagem. De acordo com Rodrigues e Calvo (2009) a EAD:

[...] descreve o universo de relaçóes professor $\mathrm{x}$ aluno quando alunos $\mathrm{e}$ instrutores estão separados no espaço e/ou no tempo. Este universo de relaçóes tem como primícias básicas: a estrutura dos programas educacionais, a interação entre alunos e professores e a natureza e o grau de autonomia do aluno (p. 3).

Desse modo, "os computadores não podem reproduzir a inteligência humana, senão, no máximo, imitá-la [...] os computadores só exibem pensamentos, já os seres conseguem pensar” (CITELLI 2002, p. 27), assim, a transação de Educação à Distância referida por Moore (2002) denomina que ocorre entre professores e alunos num ambiente que possui como característica especial a separação entre alunos e professores. Esta separação conduz a padróes especiais de comportamento. A separação entre alunos e professores afeta profundamente tanto o ensino quanto a aprendizagem.

1 O termo transacional origina-se em Dewey denotando a "interação entre o ambiente, os indivíduos e os padrốes de comportamento numa dada situação”. (BOYD; APPS, apud MOORE, 2002, p. 2). 
Com a separação surge um espaço psicológico e comunicacional a ser transposto, um espaço de potenciais mal-entendidos entre as intervençóes do instrutor e as do aluno. Este espaço psicológico e comunicacional é a distância transacional. Esta distância transacional refere-se a dois elementos chaves da educação, que possuem uma relação inversamente proporcional: a estrutura (grau de abertura) e o diálogo (grau de presença).

Assim, a estrutura de um curso a distância pode ser mais ou menos flexível, considerando os seus objetivos, as estratégias de ensino e os métodos de avaliação. De acordo com Maranhe e Debieux (2010, p. 9), existem três aspectos que estão relacionados com o êxito do uso das TIC nos AVA, são eles:

- Demanda dos alunos: os alunos (especialmente os de curso superior) têm, hoje, um grau de inclusão digital muito maior, sentindo-se à vontade para navegar nestes ambientes virtuais;

- Horário dos alunos: aumenta cada vez mais o número de alunos que trabalha, diminuindo, assim, o tempo disponível para os estudos. A partir destes ambientes virtuais é possível adequar horários de trabalho às atividades de um curso;

- Otimização de cursos: se bem usado, os ambientes virtuais podem tornar as aulas mais eficazes e melhores com o uso das várias ferramentas de interatividade disponibilizadas.

O estudo a partir dos AVA permite relaçóes cognitivas importantes, favorecendo a aprendizagem por meio da mediação pedagógica nos ambientes de interação entre alunos-professores, através das interaçóes e diálogos que aproximam no decorrer do curso. A relação de interação alunos-professores e alunos-alunos facilita a mitigação da distância transacional e possibilita a maior autonomia dos educandos.

A Educação à Distância cada vez mais cresce no sentido de atender às demandas da sociedade contemporânea, e tem se voltado para um público que não pode estudar em turmas regulares. Assim, é ressaltada a importância 
de processos de aprendizagem autônomos e autodirigidos, voltados para esta população em educação permanente.

Quando o trabalho acontece em conjunto, o conhecimento torna-se mais profundo e facilita o desenvolvimento da aprendizagem, possibilitando ao sujeito deixar de ser independente para se tornar interdependente a partir de um processo de aprendizagem atuante. "A colaboração e o trabalho em conjunto fornecem o alicerce para a capacidade de o estudante envolver-se com um processo de aprendizagem transformador" (PALLOFF, PRATT, 2002, p.157).

Assim, no processo de ensino da $\mathrm{EAD}$, os estudantes são responsáveis por seu próprio rendimento e no auxílio à aprendizagem dos demais integrantes do grupo, portanto, o sucesso ou a falha no processo de ensinoaprendizagem depende da interação não somente entre aluno-professor, mas também entre aluno-aluno. Neste processo de ensino, o sucesso está intrinsicamente ligado ao domínio das TIC, que de forma geral, pode ser um entrave ao resultado desejável através do uso da EAD. Assim, como afirma Pinto (2002):

A utilizaçáo de tecnologias de informação e comunicação conduz-nos inevitavelmente a outro tipo de problemas. O estudante a distância precisa de aprender não só as matérias objeto do seu estudo, mas também a dominar as tecnologias com que vai trabalhar. Esta tarefa, se executada isoladamente, pode conduzir a uma situação de frustraçáo que acabará por ter repercussōes no sucesso, quer do aluno, quer do próprio curso. É assim importante que o aluno se sinta apoiado quer no que toca o conteúdo a aprender, quer na utilização das tecnologias que lhe permitem essa aprendizagem (p.25).

Portanto, os AVA como processo de ensino-aprendizagem requerem atenção em seu uso. Dias (2004) destaca dois modelos de aprendizagem, o primeiro fundamenta-se na ideia de que a transmissão de informação é a base da educação; neste caso o aluno aprende aquilo que lhe é ensinado 
a partir de um foco de transmissão, entrando em contato com o professor para retirar eventuais dúvidas.

O segundo trata do modelo colaborativo que segue o princípio de que a interação e o diálogo entre alunos e professores é o essencial para o processo educativo, ou seja, o aprendizado ocorre através da construção coletiva a partir do questionamento, problematização, discussão, apresentação de dúvidas e troca de informaçóes.

Todos os modelos de aprendizagem evidenciam abordagens pedagógicas que coexistem na EAD. A coexistência, ou ainda, a convivência de modelos distintos justifica-se na intencionalidade das propostas de EAD vigentes; assim, a escolha da abordagem adequa-se aos objetivos propostos no Projeto Político-Pedagógico de cada instituição formadora.

A utilização das tecnologias de informação e de comunicação para criação de ambientes que proporcionem melhores condiçóes para a aquisição e construção do conhecimento tem trazido mudanças fundamentais nas formas de trabalho docente. Assim, "a importância da utilização da tecnologia computacional na área educacional é indiscutível e necessária, seja no sentido pedagógico, seja no sentido social" (TAJRA, 2000, p. 18). Estas tecnologias trazem cada vez mais recursos e oportunidades para que educadores e estudantes sejam protagonistas, possam aprender e ensinar gerando novos conhecimentos.

A incorporação das TIC na educaçãa propiciou o desenvolvimento dos ambientes virtuais de aprendizagem como novos meios de apoio ao aprendizado à distância, já que possibilitam a troca de informaçóes, a comunicação, a interação e a disponibilização de materiais de estudo. Por isso, é importante caracterizar os AVA como um ambiente de ensino-aprendizagem, além de apresentar seu potencial e aplicações didático-pedagógicas.

Dessa forma, entre as vantagens que a EAD proporciona em relação ao ensino presencial (tradicional), podemos citar os apontamentos de Silva (2005, p. 3): 
- Interatividade: em salas de aula, a interatividade fica restrita ao limite físico e temporal, o que não ocorre com os recursos pela Web, em que não há restriçóes de localização e, quanto ao fator temporal, o estudante pode acessar a Internet a qualquer horário.

- Ensino independente de tempo e lugar: o treinamento pode ser feito em qualquer lugar a qualquer momento, como explicado no item anterior. O alcance é limitado pelo alcance da Internet.

- Minimização de deslocamentos: não há necessidades de deslocamentos frequentes para locais físicos predeterminados, o que também determina uma redução de custos sobre o transporte, alimentação e hospedagem.

- Economia de tempo: por haver uma minimização de deslocamentos, há, consequentemente, uma redução de tempo.

- Atendimento em massa personalizado (mass customization): é a possibilidade de oferecimento de ensino em massa com a adequação às características dos alunos.

- Possibilidade de determinaçáo, pelo aluno, de seu ritmo de aprendizagem: o que faz com que o indivíduo possa ter um papel ativo sobre o ritmo e necessidades de aprendizagem.

- Network: possibilita e promove a troca de experiências, criando uma comunidade virtual. Essa troca enriquece, estimula e dinamiza o aprendizado dos alunos

As vantagens disponíveis através da EAD aliadas à possibilidade de qualidade no ensino são os atrativos que convertem esta modalidade de ensino à nova opção de formação e qualificação profissional. Os AVA vem tomando na educação um espaço que não pode ser desprezado. Atualmente, o computador já é utilizado amplamente como meio de ensino. A tabela a seguir ilustra as diferenças no processo ensino-aprendizagem entre a EAD e a educação presencial. 


\section{Tabela 1 - Comparaçáo entre visóes do ensino presencial e do ensino virtual}

\begin{tabular}{|c|c|c|}
\hline Categoria & Visóes do ensino presencial & Visões ensino virtual \\
\hline Conhecimento & $\begin{array}{l}\text { Transdisciplinar, procedimental, } \\
\text { orientado para solução de } \\
\text { problemas. }\end{array}$ & $\begin{array}{l}\text { Transdisciplinar, procedimental, } \\
\text { orientado para solução de } \\
\text { problemas. }\end{array}$ \\
\hline $\begin{array}{l}\text { Fontes de } \\
\text { informaçáo }\end{array}$ & Todas. & Todas. \\
\hline $\begin{array}{l}\text { Papel do } \\
\text { docente }\end{array}$ & $\begin{array}{l}\text { Facilitar a aprendizagem dos } \\
\text { alunos, orientar a investigação, } \\
\text { provocar questionamentos, } \\
\text { supervisar o progresso. }\end{array}$ & $\begin{array}{l}\text { Facilitar a aprendizagem dos } \\
\text { alunos, orientar a investigação, } \\
\text { provocar questionamentos, } \\
\text { supervisar o progresso. }\end{array}$ \\
\hline Papel do aluno & $\begin{array}{l}\text { Responsável por sua } \\
\text { aprendizagem, construtor de } \\
\text { conhecimento, provedor de } \\
\text { sentido. Coloca e recoloca } \\
\text { problemas, perguntas, } \\
\text { hipóteses; leva a cabo projetos } \\
\text { de indagaçáo; busca, seleciona, } \\
\text { avalia e interpreta informação; } \\
\text { elabora respostas, chega a } \\
\text { conclusóes, e comunica o } \\
\text { processo e o resultado de sua } \\
\text { aprendizagem. }\end{array}$ & $\begin{array}{l}\text { Responsável por sua aprendizagem, } \\
\text { construtor de conhecimento, } \\
\text { provedor de sentido. Coloca e } \\
\text { recoloca problemas, perguntas, } \\
\text { hipóteses; leva a cabo projetos de } \\
\text { indagação; busca, seleciona, avalia } \\
\text { e interpreta informação; elabora } \\
\text { respostas, chega a conclusóes, e } \\
\text { comunica o processo e o resultado } \\
\text { de sua aprendizagem. }\end{array}$ \\
\hline Lugar & $\begin{array}{l}\text { A sala de aula, biblioteca, } \\
\text { laboratório de computadores, } \\
\text { casa, etc. }\end{array}$ & $\begin{array}{l}\text { A sala de aula, biblioteca, } \\
\text { laboratório de computadores, casa, } \\
\text { os AVA, a virtualidade, a internet. }\end{array}$ \\
\hline Avaliação & $\begin{array}{l}\text { Continuada e autêntica } \\
\text { (portfólio, ensaios, solução } \\
\text { de situações problemáticas, } \\
\text { informes de pesquisa, etc.). }\end{array}$ & $\begin{array}{l}\text { Continuada e autêntica (portfólio, } \\
\text { ensaios, solução de situaçôes } \\
\text { problemáticas, informes de } \\
\text { pesquisa, etc.). }\end{array}$ \\
\hline
\end{tabular}

Fonte: Sancho (2010, p. 105) 
Pode-se dizer que as visões denominadas de emergentes, tanto no ensino presencial quanto no virtual, revelam que o uso de recurso tecnológico e midiático na educação independe da sua implantação na escola, mas da formação do professor para lidar crítica e pedagogicamente com este recurso, bem como da capacidade de refletir sobre sua prática no desenvolvimento de suas experiências. Desse modo, Moran (2000, p. 107) diz que;

O papel do professor é fundamental nos projetos de inovaçôes, até porque a qualidade de um ambiente tecnológico de ensino depende muito mais de como ele é explorado didaticamente, do que de suas características técnicas. A simples presença de novas tecnologias não é por si só, garantia de maior qualidade na educação, pois a modernidade pode mascarar um ensino tradicional, baseado na recepção e na memorização de informaçôes.

Assim, diante da exposição das caracterizações dos ambientes presenciais e virtuais de ensino e de aprendizagem, faz se necessário refletir sobre a prática do professor e o desempenho do aluno frente aos recursos tecnológicos, sobretudo, diante dos procedimentos didático-pedagógicos adotados.

\section{AVA: o uso na educação presencial e à distância}

O termo ambiente virtual de aprendizagem (AVA) é designado para descrever o conjunto de sistemas necessários à gestáo da aprendizagem online. Tais sistemas permitem a gestão de todos os processos, desde a criação do curso até a disponibilização do material didático ao aluno. Os AVA são sistemas que fornecem suporte a diversos tipos de atividades realizadas pelo aluno e pelo professor, um conjunto de ferramentas que são usadas em diferentes situaçóes dos processos de ensino e de aprendizagem.

Podemos considerar os AVA como processos de ensino e de aprendizagem, presenciais ou à distância, ganham outras possibilidades para a organização dos cursos de maneira mais controlada. Além disso, têm potencial para possibilitar maior aproximação entre professores e alunos 
dentro do processo educativo principalmente pelo caráter individualizado dos estudos.

Assim, para Almeida (2003, p. 334), ensinar em ambientes virtuais de aprendizagem significa:

[...] organizar situaçóes de aprendizagem, planejar e propor atividades; disponibilizar materiais de apoio com o uso de múltiplas mídias e linguagens; ter um professor que atue como mediador e orientador do aluno, procurando identificar suas representaçóes de pensamento; fornecer informaçóes relevantes, incentivar a busca de distintas fontes de informações e a realização de experimentaçôes; provocar a reflexão sobre processos e produtos; favorecer a formalização de conceitos; propiciar a Inter aprendizagem e a aprendizagem significativa do aluno .

Assim, é possível perceber que os AVA podem ser utilizados tanto em atividades em ambientes on-line, quanto presenciais. Sendo que a opção de utilizar os AVA se apresenta como possibilidade viável para aumentar o nível de interaçóes entre professores e alunos ao oferecer suporte para a comunicação e troca de informações entre os participantes. Assim, "em qualquer situação de aprendizagem a interação entre os participantes é de extrema importância. É por meio das interaçóes que se torna possível a troca de experiências, o estabelecimento de parcerias e de cooperação" (MORAES 2002, p. 203).

O uso dos AVA no processo de ensino presencial, no qual professor e alunos dividem o mesmo espaço físico e a comunicação se dá de forma oral, possibilita observações das ações e reaçôes dos alunos em relação ao uso deste recurso, bem como, a avaliação da qualidade do material disponibilizado e a da interação existente nos processos de ensino e de aprendizagem. Assim

A interaçáo que se estabelece nos ambientes virtuais propicia o desenvolvimento construído dos participantes por meio de mediaçóes entre estes participantes, o meio social e o próprio ambiente, cuja influência na evoluçáo e na aprendizagem não diz respeito apenas à forma como ele foi estruturado e às respectivas informações, mas enfatiza as 
articulaçóes que se estabelecem na experiência social (ALMEIDA, 2003, p. 210).

Em relação à disciplina ofertada na modalidade semipresencial, o essencial nas atividades em AVA é que elas sejam resgatadas em sala de aula presencial, evidenciando seu significado, as habilidades, competências e atitudes exigidas por meio do ambiente virtual.

Cabe reafirmar que a utilizaçâo do ambiente virtual utilizado em um curso presencial pode se dar de maneira a agrupar procedimentos de ensino a ferramentas de interação para dinamizar os processos de ensino e de aprendizagem. Mas, é importante ressaltar que "um ambiente de aprendizagem poderá ser muito rico, porém, se o aluno não desenvolve atividades para o aproveitamento de seu potencial, nada acontecerá” (GALVIS, 1992, p. 52).

Já em ambientes totalmente virtuais, o desempenho das ferramentas utilizadas em AVA estão associados, como exposto no "XV Congresso Brasileiro de Custos” (2008, p. 19): .

a) Ao diagnostico: como sistema de informais, permite a identificação de perfis dos alunos e usuários, o que possibilita realizar uma série de diagnósticos acerca do processo de ensino-aprendizagem, além de informações acadêmicas;

b) Ao design: disponibiliza conteúdo, material didático e forma de apresentação com a possibilidade de integração de diversas mídias;

c) À implementação: permite a realização do plano de ensino e de aula;

d) À avaliação: disponibiliza ferramentas que permitem o controle e, posteriormente, análise de informaçôes acadêmicas e gestão do processo de aprendizagem a fim de que o objetivo proposto no projeto de um curso seja alcançado.

Nos portais de ensino a distancia existem múltiplos recursos que promovem a interação do aluno com a educação, a seguir temos um exemplo 
de AVA, onde vemos todos os recursos virtuais disponíveis ao aluno (por exemplo, Figura 1).

Figura 1 - Ambiente de Virtual Aprendizagem (Instituto Prominas) ${ }^{2}$

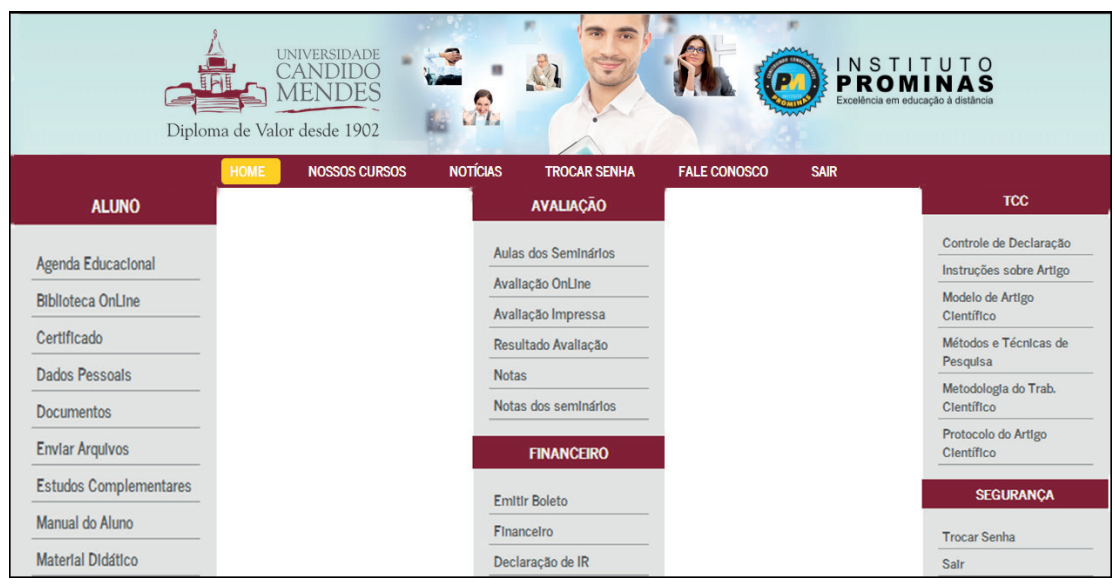

Como vimos, as TIC têm oferecido meios para desenvolver ambientes que promovam a aprendizagem, mas a tecnologia digital em si não é solução para os problemas de aprendizagem que permeiam a realidade educacional contemporânea. Mas Bettega (2005, p. 17) afirma que:

[...] o uso de tecnologia no ensino não deve se reduzir apenas à aplicaçáo de técnicas por meio de máquinas ou apertando teclas e digitando textos, embora possa limitar-se a isso, caso não haja reflexão sobe a finalidade da utilizaçâo de recursos tecnológicos nas atividades de ensino.

Mesmo com algumas divergências, os AVA são uma realidade, podemos reafirmar isso através das palavras de Silva (2011, p. 64):

$\mathrm{O}$ ambiente virtual de aprendizagem é a sala de aula online. É composto de interfaces ou ferramentas decisivas para a construção da interatividade e da aprendizagem. Ele acomoda o web-roteiro com sua trama de conteúdos

2 Fonte: Instituto Prominas. Disponível em http://ava.portalprominas.com.br/login.aspx Acesso: 28 de Fevereiro de 2014. 
e atividades propostos pelo professor, bem como acolhe a atuação dos alunos e do professor, seja individualmente, seja colaborativamente

Por isso, talvez seja melhor considerar os AVA não como uma alternativa que exclui os demais recursos didáticos, mas são complementares, uma vez que o foco da questão educacional é uma práxis pedagógica eficiente e não a mera busca de formas para desenvolver a aprendizagem, mas, a utilização da tecnologia computacional educação imprescindível. Por outro lado, também pode ser dito que os AVA, em alguns casos, náo possuem ferramentas ou estrutura suficiente para permitir interaçóes entre seus participantes. Assim,

[...] as atividades realizadas em AVA podem ser utilizadas como um caminho para promover a autonomia, sistematizar o conhecimento, possibilitar a exploração de espaços virtuais e recursos virtuais e avaliação formativa. (ARAÚJO JR; MARQUESI, 2008, p. 358).

Essas possibilidades associadas a um conjunto de intençóes e numa práxis que tenha como objetivo a construção de conhecimento, potencializa a capacidade do sujeito de compreender e aprender. Assim as TIC atuais oferecem meios facilitadores, mas, de forma isolada, não garantem em absoluto novas formas de ensinar, pensar e conviver.

O que se tem agora é a oportunidade de desenvolver um ambiente com a possibilidade técnica de entrelaçar a cultura, a prática social, saberes, a prática pedagógica, a ciência, expressando-se por diferentes linguagens, na tentativa de produzir novos sentidos e, em consequência, uma nova paisagem educativa. Caso contrário, essas tecnologias servirão como estratégia para seduzir o aluno através da substituição de velhos manuais por outros de nova geração com imagens, mesmos conteúdos, sustentando assim a ilusão de que se está inovando a educação, mas na sua essência está simplesmente reeditando as velhas fórmulas de ensino.

As TIC oferecem perspectivas sem precedentes ao disponibilizar ferramentas que possibilitam criar hipertextos, armazenar conteúdos em 
banco de dados, utilizar redes comunicacionais por meio de ferramentas de interação. Elas penetram no campo educacional transformando-se em recurso pedagógico, podendo ser utilizadas como parte de um conjunto de açôes com o objetivo de ensinar e de aprender.

Portanto, surge como necessidade a reformulação dos currículos, para que dêem conta de processos de comunicação não mais unidirecionais, que superem a transmissão e a mera reprodução oral dos conhecimentos.

A noção de ensino e sua relevância, assim como o papel do professor no processo de ensino desenvolvido através dos AVA ganham dimensóes significativas, em função das possibilidades didático-pedagógicas abertas por esses ambientes. Por meio dos AVA, o acesso ao conteúdo bem como o processo de interaçấo entre o professor e o grupo de alunos pode acontecer em tempos e espaços diferenciados dos convencionais.

Assim, estudar por intermédio dos AVA possibilita o estar junto virtualmente, uma vez que atuar nesse ambiente possibilita expressar pensamentos, tomar decisóes, dialogar, trocar informaçóes e experiências e produzir conhecimento mesmo não limitando ao mesmo tempo e espaço físico.

\section{Conclusão}

Em suma, esta revisão bibliográfica indicou que a sociedade contemporânea, arraigada de tecnologias, apresenta novas demandas e que consequentemente a escola está inserida em uma nova dinâmica para o trabalho docente.

Neste sentido, a prática docente e as relaçóes entre a tecnologia e a educação, especialmente com o uso dos AVA, possibilita através das TIC estratégias de ensino e de aprendizagem capazes de aumentar a motivação, a concentração e a autonomia do estudante. 
No que diz respeito às dificuldades encontradas ao utilizar os AVA, entendemos que os processos de formação docente com suporte tecnológico envolvem desafios que só poderão ser superados com o aperfeiçoamento da prática. $\mathrm{O}$ manuseio do computador, da internet, o acesso aos conteúdos requer novas habilidades tanto dos professores, quanto dos alunos, que estão relacionados com o conhecimento e uso das TIC.

Podemos concluir que o potencial da mudança da prática didáticopedagógica não está somente nos AVA, mas principalmente na reflexão permanente do professor que avalia a sua prática com vistas ao seu aprimoramento. Os AVA possibilitam a interatividade e a comunicação por meio do diálogo e a partir das inúmeras possibilidades, é possível vivenciar um processo educativo construtivo através do ambiente virtual de aprendizagem.

\section{Referências}

ALMEIDA, M. E. B. Educação à distância na internet: abordagens e contribuiçôes dos ambientes digitais de aprendizagem. Educação e Pesquisa, São Paulo, v.29, n.2, p. 327-340, jul./dez. 2003.

ARAÚJO JR., C.F.; MARQUESI. S.C. Atividades em ambientes virtuais de aprendizagem: parâmetros de qualidade. In: LITTO, F. M.; FORMIGA, M.M.M. (Orgs.). Educação à distância: o estado da arte. São Paulo: Pearson Education do Brasil, 2009.

BeTTegA, M. H. S. A educação continuada na era digital. São Paulo: Cortez, 2005.

BRASIL. Ministério da Educação. Secretaria de Educação a Distância. Referenciais de qualidade para educação superior à distância. Brasília, DF: MEC/Seed, 2007. Disponível em: http://portal.mec.gov.br/seed/arquivos/ pdf/legislacao/refead1.pdf Acesso: 15 de Janeiro de 2014. 
BRASIL. Ministério da Educação. Decreto no 5622 - Regulamenta o Art. 80 da Lei no 9.394, de 20/12/1996, que estabelece as Diretrizes e Bases da Educação Nacional, 2005. Disponível em: http://portal.mec.gov.br/seed/ arquivos/pdf/dec_5622.pdf Acesso: 15 de Janeiro de 2014.

DIAS, A. Os primeiros cadernos. In: Dias, A. (Org.), Cadernos e-Learning: Práticas de e-Learning em Portugal. Braga:TecMinho/Gabinete de Formação Contínua da Universidade do Minho, 2004.

GALVIS P, Á. H. Ingeniería de Software Educativo. Santafé de Bogotá: Ediciones Uniandes, 1992.

MARANHE, E.A.; DEBIEUX, M. Manual Operacional do Ava UNESP. Bauru 2010. Disponível em http://www.acervodigital.unesp.br/ bitstream/123456789/210/4/Redefor_Manual_AVA.pdf Acesso: 10 de janeiro de 2014.

MEHLECKE, Q. T. C.; TAROUCO, L. M. R. Ambientes de Suporte para Educaçâo a Distância: A mediação para aprendizagem cooperativa. Novas Tecnologias na Educação, V. 1 № 1, Fevereiro, 2003. Disponível em: http://penta2.ufrgs.br/edu/ciclopalestras/artigos/querte_ambientes.pdf. Acesso: 26 de Janeiro de 2014.

MOORE, M. G. Teoria da distância transacional. [Trad. Wilson Azevêdo. Revisão de tradução: José Manuel da Silva]. Revista Brasileira de Aprendizagem Aberta e a Distância, São Paulo, Agosto 2002. Disponível em: http://www.abed.org.br/revistacientifica/Revista_PDF_Doc/2002_ Teoria_Distancia_Transacional_Michael_Moore.pdf. Acesso: 10 de janeiro de 2014.

MORAES, M.C. (Org.). Educação à distância: fundamentos e práticas. Campinas: Unicamp/Nied, 2002.

MORAN, J. M. As novas tecnologias e mediação pedagógica. São Paulo: Papirus, 2000. 
PINTO, C. A. S. Ensino à distância utilizando TICs: uma perspectiva global. In:

JAMBREIRO, O.; RAMOS, F. Internet e educação à distância. Salvador: EDUFBA, 2002. p. 15-34.

RODRIGUES, A.J.; CALVO, T.C.M. Distância transacional: sugestôes para reduzir. 2009. Disponível em: http://www.webartigos.com/artigos/ distancia-transacional-sugestoes-para-reduzir/19527/ Acesso: 22 de janeiro de 2014.

SATO, M. Educação ambiental nas comunidades (ditas) tradicionais. Palestra proferida na III Semana Temática da Biologia. São Paulo: IB/USP, 2000.

SILVA, A. C. L. Um panorama do Ensino de Graduação a Distância no Brasil. UFMG, 2000. Disponível em http://www.isoc.org/zakon/internet/history/ hit.html. Acesso: 20 de Janeiro de 2014.

SILVA, M. Educação online: teorias, práticas, legislação, formação corporativa. 3. ed. São Paulo: Ed. Loyola, 2011.

TAJRA, S. F. Informática na Educação: novas ferramentas para o professor da atualidade. 2a ed. São Paulo: Érica, 2000.

PALLOFF, R.M.; PRATT, K. Construindo comunidades de aprendizagem no ciberespaço. [Trad. Vinícius Figueira]. Porto Alegre: Artmed, 2002.

XV Congresso Brasileiro de Custos - Curitiba - PR, Brasil, 12 a 14 de novembro de 2008. Disponível em http://home.furb.br/mariadomingues/ site/publicacoes/2008/eventos/evento-2008-01.pdf 
